\title{
Ação nematicida de extratos de alho, mostarda, pimenta malagueta, de óleo de mostarda e de dois produtos à base de capsainóides e alil isotiocianato sobre juvenis de Meloidogyne javanica, (treub) Chitwood, 1949, em casa de vegetação
}

\author{
Wânia dos Santos Neves ${ }^{1}$; Leandro Grassi de Freitas ${ }^{1}$; Marcelo Magalhães Coutinho ${ }^{1}$; Rosangela Dallemole- \\ Giaretta $^{1}$; Cleia de Fátima Silva Fabry ${ }^{1}$; Onkar Dev Dhingra ${ }^{1} \&$ Silamar Ferraz $^{1}$
}

\begin{abstract}
${ }^{11}$ Departamento de Fitopatologia, Universidade Federal de Viçosa. Viçosa, MG. CEP 36571-000.
Autor para correspondência: Wânia dos Santos Neves (wanianeves@yahoo.com.br)

Data de chegada: 28/03/2005. Aceito para publicação em: 28/11/2005.
\end{abstract}

1186

\section{RESUMO}

Neves, W.S; Freitas, L.G.; Coutinho, M.M.; Giaretta-Dallemole, R.; Fabry, C.F.S.; Dhingra, O.D. \& Ferraz, S. Atividade nematicida de extratos botânicos de pimenta malagueta (Capsicum frutescens), mostarda (Brassica campestris) e alho (Allium sativum) sobre o nematóide das galhas, Meloidogyne javanica, em casa de vegetação. Summa Phytopathologica, v.35, n.4, p.255-261, 2009

O experimento teve como objetivo avaliar a atividade nematicida de extratos botânicos dos frutos de pimenta malagueta (Capsicum frutescens), plantas de mostarda (Brassica campestris), de bulbos de alho (Allium sativum) e óleo de mostarda sobre o nematóide das galhas, Meloidogyne javanica, em tomateiro em casa de vegetação e posteriormente comparar os extratos que apresentassem maior redução de número de galhas e de ovos com dois produtos à base de capsaicina, capsainóides e alil isotiocianato. Uma mistura peneirada de solo e areia na proporção 1:1 (v:v) foi colocada em vasos de plástico e infestada com 4000 ovos de $M$. javanica. Quatro dias após $20 \mathrm{~mL}$ de cada extrato, na concentração de $1000 \mathrm{ppm}$, foram espalhados sobre o solo. Apenas água foi derramada sobre o solo infestado no tratamento testemunha. Mudas de tomate com 20 dias de idade foram transplantadas quatro dias após a colocação dos extratos ao solo. Após quarenta e cinco dias avaliou-se o número de ovos e o número de galhas do sistema radicular de cada planta. Os extratos clorofórmico e cetônico de pimenta malagueta e o óleo de mostarda apresentaram melhor controle do nematóide, diferindo estatisticamente da testemunha quanto ao número de galhas. Porém, somente o óleo de mostarda reduziu significativamente o número de ovos quando comparado com a testemunha. Os extratos cetônico e clorofórmico de pimenta e o óleo de mostarda reduziram em $34,5 \%$, $40,4 \%$ e $99,9 \%$ o número de galhas, respectivamente e o óleo de mostarda reduziu em $99,9 \%$ o número de ovos. No experimento seguinte foram avaliados o extrato clorofórmico de pimenta, o óleo de mostarda, o produto comercial Champon ${ }^{\circledR}$ e um produto em desenvolvimento na UFV, chamado DS, a base de capsaicina, capsainóides e alil isotiocianato em diferentes concentrações. Os produtos Champon ${ }^{\circledR}$ e DS e o óleo de mostarda reduziram o número de ovos e galhas quando comparados à testemunha em todas as concentrações testadas. O extrato de pimenta apresentou o melhor resultado na concentração de $400 \mathrm{ppm}$, reduzindo o número de ovos e galhas em relação à testemunha, porém esse foi bem maior quando comparado com os demais produtos testados.

Palavras-chave adicionais: controle, extratos botânicos, $M$. javanica, tomateiro.

\section{ABSTRACT}

Neves, W.S; Freitas, L.G.; Coutinho, M.M.; Giaretta-Dallemole, R.; Fabry, C.F.S.; Dhingra, O.D. \& Ferraz, S. Nematicidal activity of extracts of red hot chili pepper, mustard and garlic on Meloidogyne javanica in green house. Summa Phytopathologica, v.35, n.4, p.255-261, 2009

The experiment had the objectives of evaluate the nematicidal activity of botanical extracts of chili pepper fruits (Capsicum frutescens), mustard (Brassica campestris) and garlig (Allium sativum) on the rootknot nematode, Meloidogyne javanica in tomato plants in the greenhouse, and in a second step, to compare the best extracts for the reduction of the number of eggs and root galls with two products containing capsaicin, capsainoids and allyl isothiocyanate. A sieved mixture of soil and sand 1:1 (v:v) was used to fill plastic pots and infested with 4000 eggs of $M$. javanica. After 4 days, $20 \mathrm{~mL}$ of one of the extracts, in the concentration of $1000 \mathrm{ppm}$, were poured over the soil of each pot. Water was poured in the test treatment. Twenty day-old tomato seedlings were planted, one per pot, four days after the aplication of the extracts. Forty five days after planting, the number of galls and eggs per plant was evaluated. The chloroformic and cetonic extracts of chili pepper and the mustard oil presented the highest effect on the nematode population, differing from the control treatment in respect to the number of galls, but only the mustard oil differed from the control in the number of eggs per plant. The chloroformic and cetonic extracts of chili pepper and the mustard oil reduced in $34,5 \%, 40,4 \%$ and $99,9 \%$ the number of galls, respectively, and the mustard oil reduced the number of eggs in $99,9 \%$. In the following experiment, the chloroformic extract of chili pepper, the mustard oil, a commercial product $\left(\right.$ Champon ${ }^{\circledR}$ ) and a product in development at the UFV called DS, both containing capsaicin, capsainoids and allyl isothiocyanate, were compared at different concentrations. The Champon ${ }^{\circledR}$, the DS and the mustard oil reduced the egg and gall numbers in comparison with the control treatment in all the tested concentrations. The pepper extract show the best result at $400 \mathrm{ppm}$, reducing the number of galls and eggs per root system in relation to the control treatment, however, these numbers were much higher than the observed in the Champon ${ }^{\circledR}$ and the DS treatments.

Keywords: control, botanical extracts, $M$. javanica, tomato. 
Os nematóides do gênero Meloidogyne, também conhecidos como nematóides das galhas, são considerados, segundo Sasser \& Frekman (24), os mais importantes do mundo. Estes nematóides causam grandes perdas em olerícolas, principalmente na cultura do tomate, onde as perdas chegam a 18 milhões de toneladas de frutos por ano conforme relatado por Sasser (23).

O controle de nematóides é muito complexo. Primeiramente, medidas preventivas devem ser tomadas, evitando a introdução destes organismos em áreas onde ainda não estão presentes. Métodos alternativos de controle como o uso de extratos de diferentes espécies e partes de plantas têm sido estudados para o manejo de nematóides fitoparasitas. O efeito de extratos botânico sobre os fitonematóides e algumas plantas tem apresentado um grande potencial como matéria prima para a produção de nematicidas naturais como tem sido descrito por Mani \& Chitra (12); Goswami \& Vijayalakshmi (6); Rao \& Reddy (22); Hussaini et al. (8); Ferris \& Zheng (4). Segundo Lewis \& Papavizas (11), espécies de brássicas produzem compostos sulfurosos com efeito nematicida, os glicosinolatos, incluindo isotiocianatos, nitrilas, tiocianatos e epinitrilas (14). A presença de constituintes tóxicos a nematóides no alho foi observada por Nath et al. (16) e Gupta \& Sharma (7). Freitas et al. (5) observaram grande redução na redução de ovos e na formação de galhas de Meloidogyne javanica em tomateiro, com o uso de um produto à base de capsaicina, capsainóides e alil isotiocianato.

Este trabalho teve como objetivos avaliar a atividade nematicida de extratos botânicos de pimenta malagueta (Capsicum frutescens), mostarda (Brassica campestris) e alho (Allium sativum) sobre o nematóide das galhas, Meloidogyne javanica, em tomateiro; comparar o efeito dos extratos botânicos selecionados com um produto comercial (Champon ${ }^{\circledR}$ ) e um produto em desenvolvimento na UFV, chamado DS, contendo capsaicina, capsainóides e alil isotiocianato, em diferentes concentrações, sobre M. javanica em tomateiro em casa de vegetação.

\section{MATERIAL E MÉTODOS}

\section{Parte 1: Obtenção dos extratos}

-Extrato cetônico de pimenta malagueta (Capsicum frutescens): Um quilograma de frutos frescos de pimenta malagueta foi separado em sacos de papel contendo 50 gramas de pimenta. Os sacos contendo a pimenta foram colocados em estufas de ar forçado, com temperatura ajustada em $50^{\circ} \mathrm{C}$, até atingir peso constante. Os frutos foram moídos em liquidificador e submetidos à extração com acetona em aparelho tipo Soxhlet por um período de aproximadamente 20 horas a uma temperatura de aproximadamente $50^{\circ} \mathrm{C}$. O solvente foi eliminado sob pressão reduzida em evaporador rotatório. O extrato concentrado obtido foi mantido sob refrigeração até o momento do ensaio biológico.

-Extrato cetônico de mostarda (Brassica campestris): Plantas de mostarda (folhas, flores e sementes) frescas foram fragmentadas em pequenos pedaços e colocadas em local fechado em condição de temperatura controlada, ao abrigo de luz, onde permaneceram por aproximadamente 15 dias para a secagem do material vegetal. A extração foi feita através do uso do solvente acetona em aparelho tipo Soxhlet por um período de aproximadamente 20 horas, a uma temperatura de aproximadamente $50^{\circ} \mathrm{C}$. Após este período o solvente foi eliminado sob pressão reduzida em evaporador rotatório. O extrato concentrado obtido foi mantido sob refrigeração até o momento do ensaio biológico.

-Extrato cetônico de alho (Allium sativum): Um quilograma de bulbos de alho, sem casca, foi triturado em liquidificador e colocado em 3 litros de acetona em um Erlenmeyer tampado, em repouso no escuro por aproximadamente 4 dias. Sulfato de magnésio foi adicionado na amostra antes de ser submetido à filtragem em papel de filtro. A amostra foi levada para o condensador para a eliminação do solvente. O extrato concentrado de alho obtido foi armazenado em freezer até o momento do ensaio biológico.

-Extrato clorofórmico de pimenta: $\mathrm{O}$ extrato clororfórmico de pimenta foi submetido ao mesmo processo de extração do extrato cetônico de pimenta e armazenado em local fresco ao abrigo de luz até o momento do ensaio biológico.

Óleo de mostarda: O extrato comercial de mostarda (óleo de mostarda) é um produto importado que contém, de acordo com o fabricante, aproximadamente $95 \%$ de alil isotiocianato.

Parte 2: Observação da ocorrência de fitotoxidez em tomateiro com diferentes concentrações dos extratos

Foi realizado um teste preliminar com diferentes concentrações dos extratos para verificar qual a concentração máxima do extrato que a planta suporta, sem que ocorra fitoxidez.

Os extratos foram aplicados nas concentrações de 250, 500, $750 \mathrm{e}$

$1000 \mathrm{ppm}$ por litro de solo. A emulsificação dos extratos foi feita com $1 \%$ de Tween 80 sob agitação pelo tempo de 2 minutos em agitador magnético. Foram usados vasos de plásticos de 1,5 litro de capacidade. Cada vaso recebeu uma mistura de solo e areia, previamente peneirada e tratada com brometo de metila, na proporção de 1:1 (v: v).

O teste preliminar, nas concentrações citadas anteriormente, foi feito aplicando-se à superfície do solo de cada vaso $20 \mathrm{~mL}$ dos extratos cetônicos de alho, mostarda e pimenta, extrato clorofórmico de pimenta e óleo de mostarda. Água foi usada como controle. De cada concentração foram feitas quatro repetições.

Após 4 dias da aplicação do extrato foi plantado uma muda de tomate Santa Cruz 'Kada' com 20 dias de idade. As plantas ficaram sob observação durante 15 dias.

Parte 3: Seleção dos extratos com efeito nematicida sobre $M$. javanica

Os efeitos dos extratos de pimenta, de mostarda e de alho sobre Meloidogyne javanica foram investigados em casa de vegetação quanto a redução de galhas e ovos em raízes de tomateiro. Foram usados vasos de plástico de 1,5 litro de capacidade, nos quais foi colocada uma mistura peneirada de solo e areia, previamente tratados com brometo de metila, na proporção de 1:1 (v: v). O solo de cada vaso foi infestado com uma suspensão contendo 4000 ovos de $M$. javanica, vertida através de orifícios abertos no solo, usando-se pipeta semiautomática. Quatro dias após a infestação do solo, aplicou-se, na forma de rega, $20 \mathrm{~mL}$ dos extratos cetônicos de alho, mostarda e pimenta, extrato clorofórmico de pimenta e óleo de mostarda na concentração de 1000 ppm por litro de solo. Foi feito um controle com água+tween 80 a 1\%, que foi utilizado para emulsificação dos extratos, e um controle apenas com água. Quatro dias após a aplicação dos extratos no solo, foi plantada uma muda de tomate suscetível ao nematóide (Santa Cruz 'Kada'), de 20 dias de idade, em cada vaso. As plantas foram cultivadas por um período de 45 dias, recebendo os tratos culturais necessários. Os vasos foram mantidos em casa de vegetação e irrigados sempre que necessário. Os ovos utilizados foram extraídos segundo o método Hussey e Barker, adaptado por Boneti \& Ferraz (2), obtidos a partir de raízes de tomateiro do grupo Santa Cruz, mantidos em casa de vegetação.

Após 45 dias do transplantio das mudas a parte aérea das plantas 
foi eliminada e as raízes coletadas para avaliação do número de galhas e do número de ovos. Para a contagem do número de galhas/sistema radicular, as raízes foram armazenadas em geladeira até o momento da avaliação. Para a retirada dos ovos do sistema radicular, as raízes de cada planta foram agitadas em hipoclorito na concentração de $0,5 \%$, durante 3 minutos. A seguir, os ovos foram coletados em peneira de $0,025 \mathrm{~mm}$ de abertura (500 mesh) e enxaguados em água corrente até a retirada do $\mathrm{NaOCl}$ da suspensão de ovos e guardados em tubos plásticos armazenados na geladeira até o momento da avaliação. Os ovos foram contados com o auxílio de câmara de Peters e microscópio estereoscópio.

Foram feitas dez repetições de cada tratamento em delineamento inteiramente casualizado e os dados obtidos foram submetidos a análise estatística através do sistema SAEG (3). As médias dos tratamentos foram comparadas pelo teste de Tukey a 5\% de probabilidade.

Esse experimento foi repetido apenas com os tratamentos extrato clorofórmico de pimenta e óleo de mostarda, na concentração de 1000 ppm, para confirmar o resultado anterior, pois estes reduziram significativamente a população do nematóide. Foram usados os mesmos procedimentos descritos para a montagem e avaliação do experimento anterior.

Parte 4: Comparação de diferentes concentrações dos extratos com um produto comercial e outro em desenvolvimento, ambos contendo capsaicina, capsainóides e alil isotiocianato

O experimento foi realizado em casa de vegetação, onde foi comparado o efeito dos extratos de pimenta e de óleo de mostarda, com um produto comercial (Champon ${ }^{\circledR}$ ) e com um produto em desenvolvimento na UFV, chamado DS, ambos contendo capsaicina, capsainóides e alil isotiocianato, em diferentes concentrações, sobre M. javanica em tomateiro.

Os extratos foram testados nas concentrações de 400, 200, 100 e $50 \mathrm{ppm}$ por litro de solo, indicando, respectivamente, 40, 20, 10 e 5\% da concentração previamente utilizada. Os produtos Champon® e DS também foram usados na concentrações de 40, 20, 10 e 5\%.

O experimento foi conduzido como descrito anteriormente. Após 45 dias do transplantio das mudas foram avaliados, além do número de ovos e do número de galhas, também o peso e a altura das plantas. Foram feitas dez repetições de cada tratamento em delineamento inteiramente casualizado e os dados obtidos para altura e peso da parte aérea foram submetidos a análise estatística através do sistema SAEG (3). As médias foram comparadas pelo teste de Tukey a 5\% de probabilidade. Os dados relativos aos números de ovos e de galhas foram submetidos à análise estatística descritiva, já que os dados não seguiram a distribuição normal.

\section{RESULTADOS E DISCUSSÃO}

No teste preliminar realizado, observou-se que a concentração de 1000 ppm de todos os extratos não resultou em fitotoxidez durante 15 dias em casa de vegetação.

Os resultados do experimento para seleção dos extratos, na concentração de 1000 ppm estão na Tabela 1. A análise dos resultados demonstra que não houve influência do Tween 80 a $1 \%$ sobre a população do nematóide. Observou-se a potencialidade de alguns extratos para o controle de $M$. javanica. O óleo de mostarda na concentração de 1000 ppm merece atenção especial, pois o valor
Tabela 1: Efeito de diferentes extratos aplicados ao solo, na concentração de 1000 ppm, sobre o número de galhas e de ovos de Meloidogyne javanica, presentes no sistema radicular de tomateiro grupo Santa Cruz 'Kada'

\begin{tabular}{lrr}
\hline Tratamentos & \multicolumn{2}{c}{$\begin{array}{c}\text { Meloidogyne javanica } \\
\text { Galhas }\end{array}$} \\
\hline Testemunha (água) & $425,9 \mathrm{ab}$ & $373.004,5 \mathrm{ab}$ \\
Tween 80 a 1\% & $345,8 \mathrm{bc}$ & $492.360,5 \mathrm{a}$ \\
Extrato Cetônico de Alho & $306,4 \mathrm{bc}$ & $269.076,0 \mathrm{ab}$ \\
Extrato Cetônico de Mostarda & $512,4 \mathrm{a}$ & $377.373,0 \mathrm{ab}$ \\
Óleo de Mostarda & $0,5 \mathrm{~d}$ & $143,6 \mathrm{c}$ \\
Extrato Cetônico de Pimenta & $279,0 \mathrm{c}$ & $232.134,0 \mathrm{ab}$ \\
Extrato Clorofórmico de Pimenta & $254,0 \mathrm{c}$ & $214.606,0 \mathrm{ab}$
\end{tabular}

Médias de dez repetições.

Médias seguidas pela mesma letra, nas colunas, não diferem entre si pelo teste Tukey $(\mathrm{P} \leq$ $0,05)$.

máximo observado foi de 0,5 galhas de $M$. javanica e de 143,6 ovos nas raízes de tomateiro, o que significa uma redução de $99,9 \%$ no número de galhas e de $99,9 \%$ no número de ovos (Tabela 1 ).

$\mathrm{O}$ extrato cetônico e o extrato clorofórmico de pimenta também apresentaram efeito sobre a população do nematóide reduzindo o número de galhas em relação à testemunha, porém, a redução não foi tão expressiva quanto à apresentada pelo o óleo de mostarda. A redução do número de ovos e de galhas, respectivamente, com o extrato clorofórmico de pimenta foi de $40,2 \%$ e $42,5 \%$ e com o extrato cetônico de pimenta foi de $34,5 \%$ e $37,8 \%$, porém, não houve diferença significativa entre o número de ovos desses tratamentos e da testemunha (Tabela 1).

O extrato cetônico de alho não promoveu redução na população do nematóide nesse experimento. Tarjan (27) também relatou que extratos de alho e cebola não demonstraram eficiência no controle de M. incognita. Resultados contraditórios foram obtidos por Sukul et al. (26), que observaram que extrato de alho promoveu uma considerável redução do número de galhas em plantas inoculadas $\operatorname{com} M$. incognita, porém, a aplicação do extrato ao solo causou certa fitotoxidez. A aplicação de extratos obtidos das folhas de Allium sativum e A. cepa, em pré-plantio, causou a redução do número de galhas em raízes de tomateiro (13). Parada \& Guzmán (20) também relataram o efeito do extrato de alho na redução do índice de galhas e de ovos produzidos por M. incognita em plantas de feijão (Phaseolus vulgaris).

O extrato cetônico de mostarda possibilitou reprodução do nematóide equivalente à testemunha (Tabela 1). Esse resultado difere dos resultados encontrados por Lewis \& Papavizas (11) que relatam o controle de patógenos de plantas por espécies de brássicas, atribuído à produção de compostos sulfurosos, os glicosinolatos. Poter et al. (21) observaram que tecidos foliares de Brassica spp. causaram a morte de até 95,2\% de Pratylenchus neglectus enquanto que tecidos radiculares resultaram em até $48,3 \%$ de mortalidade do nematóide. Papavizas (18 e 19) observou uma considerável redução de Aphanomyces euteicles, causador da podridão de raiz em ervilha, quando foram incorporados ao solo em casa de vegetação folhas e talos de crucíferas, tais como, repolho, mostarda, couve e nabo.

A ineficiência dos extratos de alho e mostarda aqui demonstrada pode ser atribuída à ausência ou à baixa concentração dos compostos com atividade nematicida, como os compostos sulfurosos, isotiocianatos, nitrilas, tiocianatos e epinitrilas. Os métodos de extração usados podem ter feito com que tais compostos não tenham sido retirados dos vegetais na quantidade adequada para atuar sobre os 
Tabela 2: Efeito de diferentes extratos aplicados ao solo, na concentração de 1000 ppm, sobre o número de galhas e de ovos de Meloidogyne javanica, presentes no sistema radicular de tomateiro grupo Santa Cruz 'Kada' (reavaliação dos extratos que se mostraram eficientes).

\begin{tabular}{lrr}
\hline Tratamentos & \multicolumn{2}{c}{ Meloidogyne javanica } \\
& Galhas & Ovos \\
\hline Testemunha (água) & $874,7 \mathrm{a}$ & $364.596,1 \mathrm{a}$ \\
Óleo de Mostarda & $0,8 \mathrm{c}$ & $431,3 \mathrm{c}$ \\
Extrato Clorofórmico de Pimenta & $378,8 \mathrm{~b}$ & $100.279,9 \mathrm{~b}$ \\
\hline
\end{tabular}

Médias de dez repetições.

Médias seguidas pela mesma letra, nas colunas, não diferem entre si pelo teste Tukey $(\mathrm{P} \leq$ $0,05)$.

nematóides. Foi observado por Scramin et al. (25) que a atividade nematicida de algumas espécies depende do solvente utilizado na extração dos seus produtos e da parte da planta utilizada. Mayton et al. (14) observaram que o composto alil isotiocianato não foi detectado em macerados de tecidos foliares de Brassica campestris enquanto que em outras espécies e partes de brássicas o composto estava presente. Nidiry et al. (17) demonstraram a diferença da atividade nematicida entre extratos metanólicos de sementes de cebola obtidos a quente e a frio, onde a taxa de mortalidade de juvenis de $M$. incognita in vitro foi de $100 \%$ e $12 \%$, respectivamente. Os autores sugerem que a retirada do princípio ativo é mais eficiente no método de extração a quente.

Foi feita uma reavaliação dos extratos aplicados ao solo que se mostraram eficientes na concentração de $1000 \mathrm{ppm}$ onde avaliou-se o efeito de tais extratos sobre o número de galhas e de ovos de Meloidogyne javanica, presentes no sistema radicular do tomateiro (Tabela 2).

No experimento onde foi feita a comparação de diferentes concentrações dos extratos e dos produtos contendo capsaicina, capsainóides e alil isotiocianato, o óleo de mostarda reduziu drasticamente o número de ovos e de galhas em todas as concentrações (Figuras 1 e 2). Na concentração de $5 \%$ o número de ovos apresentou uma redução de $97,8 \%$ e o número de galhas uma redução de $93,7 \%$ quando comparados à testemunha. Houve uma redução de $99,9 \%$ tanto no número de ovos quanto no número de galhas em relação à testemunha nas concentrações de $10 \%$ (Figuras 3 e 4), 20\% (Figuras 5 e 6) e $40 \%$ (Figuras 7 e 8 ). Nas concentrações de $5 \%$ e $10 \%$ a altura e o peso da parte aérea das plantas apresentaram médias significativamente maiores que a testemunha (Tabela 3). Nas concentrações de $20 \%$ e 40 o peso e a altura da parte aérea das plantas não diferiram da testemunha (Tabela 3). Husain et al. (8) já haviam realizado um estudo onde observaram a eficácia da torta de mostarda no controle de $M$. incognita e que o produto também não interferiu no crescimento das plantas. Akhtar \& Mahmood (1) observaram que o óleo de mostarda também reduziu a população $M$. incognita em tomateiro, mas apresentou um desenvolvimento da planta maior do que o observado em plantas inoculadas apenas com o nematóide.

O extrato clorofórmico de pimenta reduziu o número de galhas e de ovos nas concentrações 200 e 400 ppm, mas o melhor resultado foi apresentado pela concentração de 400 ppm, onde houve uma redução de $23,5 \%$ e $45,5 \%$ no número de galhas e ovos, respectivamente (Figuras 7 e 8). Em nenhuma das concentrações a pimenta causou fitotoxidez em relação a altura e peso da parte aérea das plantas (Tabela 3). Sulkul et al. (26) também não observaram a ocorrência de fitotoxidez causada por extrato de pimenta chinesa (Capsicum annum) e relataram o seu efeito na diminuição do número de galhas formadas por $M$. incognita. Moreira \& Freitas (15) não observaram efeito do extrato aquoso de pimenta malagueta sobre a infectividade de $M$. javanica em raízes de tomateiro, altura e peso da parte aérea. Neste caso, a pimenta pode não ter exercido efeito sobre o nematóide devido ao baixo teor de capsaicina e capsainóides presentes no filtrado.

O produto Champon ${ }^{\circledR}$ apresentou alta eficência no controle de M. javanica em tomateiro em todas as concentrações testadas. $\mathrm{O}$ número de galhas e de ovos foi, respectivamente, $52,9 \%$ e $80,6 \%$ menor do que os apresentados pela testemunha com o produto na concentração de 5\% (Figuras 1 e 2). O peso e altura das plantas na concentração de $5 \%$ foram superiores aos apresentados pela testemunha (Tabela 3). Na concentração de $10 \%$ o produto apresentou uma redução

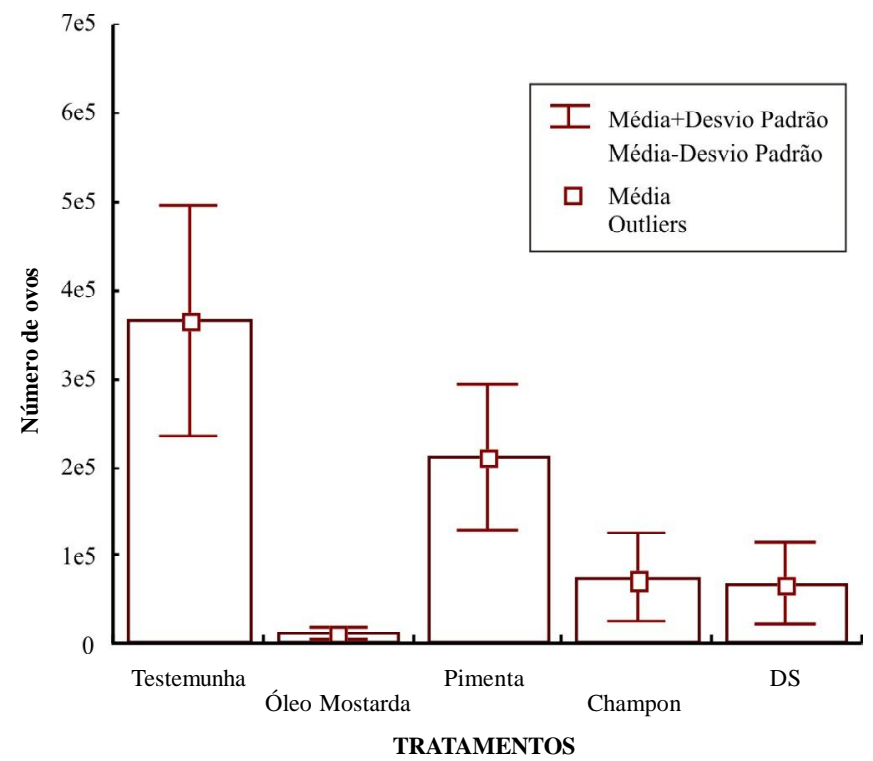

Figura 1: Número de ovos de Meloidogyne javanica em raízes de tomateiro retiradas de solo tratado com extratos na concentração de $50 \mathrm{ppm}$ e dos produtos na concentração de $5 \%$.

Tabela 3: Efeito de diferentes extratos e produtos sobre a altura e o peso da parte aérea das plantas de tomate grupo Santa Cruz 'Kada'

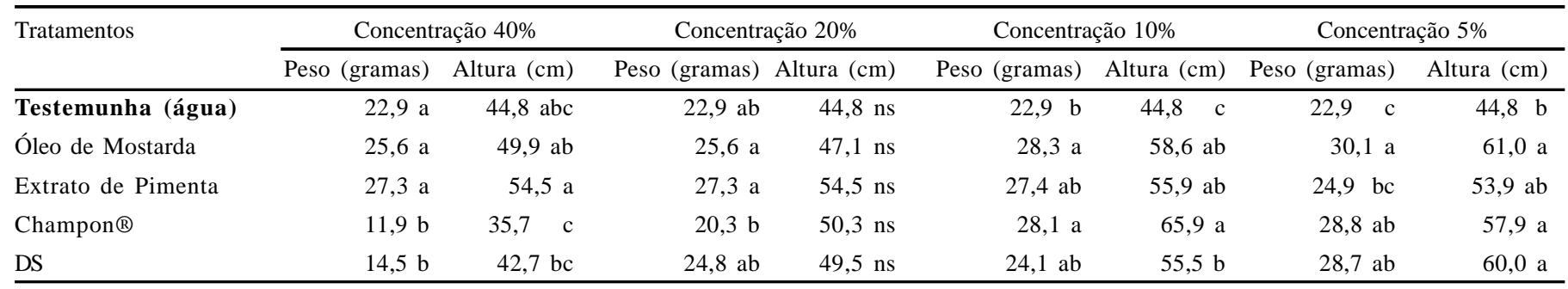

Médias de dez repetições.

Médias seguidas pela mesma letra, nas colunas, não diferem entre si pelo teste Tukey ( $\mathrm{P} £ 0,05)$

${ }^{\mathrm{n} s}$ Médias dos tratamentos desta coluna não diferiram significativamente pelo teste de Tukey $(\mathrm{P} £ 0,05)$. 


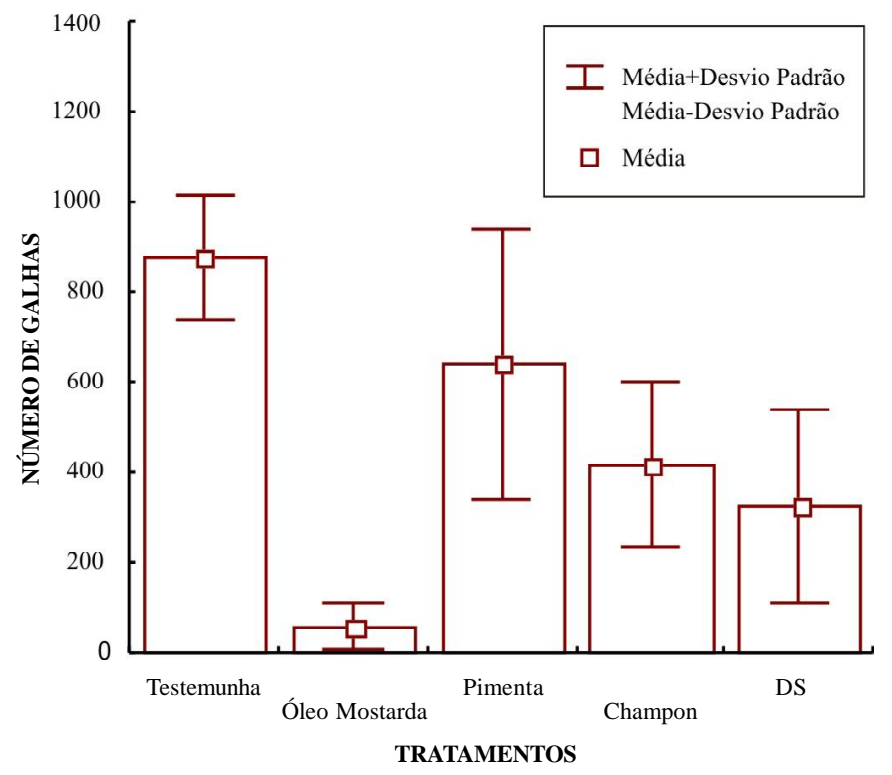

Figura 2: Número de galhas formadas por Meloidogyne javanica em raízes de tomateiro retiradas de solo tratado com extratos na concentração de $50 \mathrm{ppm}$ e dos produtos na concentração de $5 \%$.

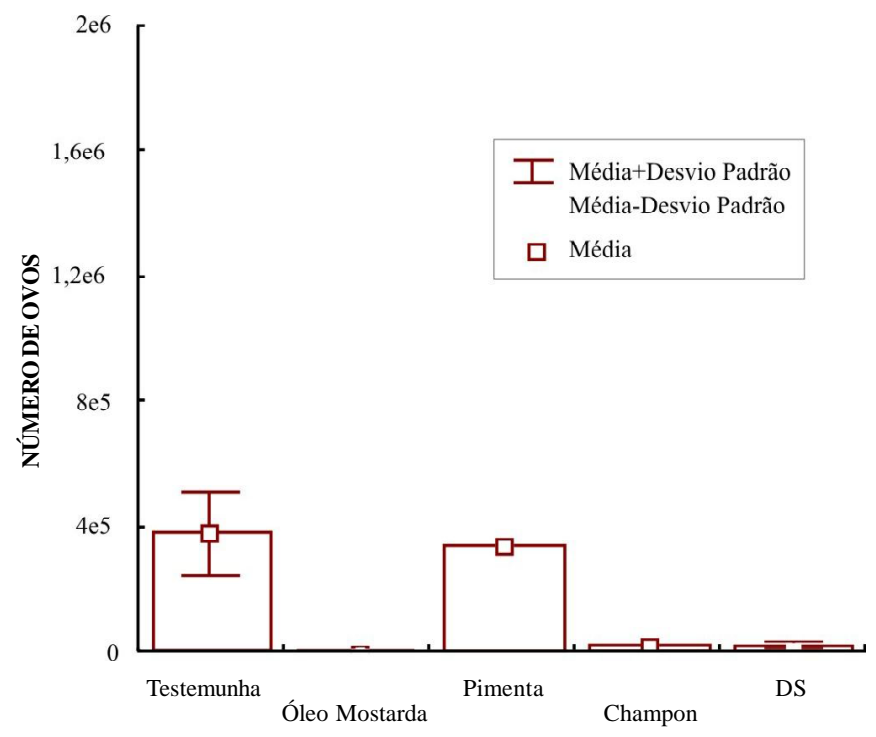

TRATAMENTOS

Figura 3: Número de ovos de Meloidogyne javanica em raízes de tomateiro retiradas de solo tratado com extratos na concentração de 100 ppm e dos produtos na concentração de $10 \%$.

média de $95,1 \%$ no número de ovos e de $87,4 \%$ no número de galhas quando comparados à testemunha (Figuras 3 e 4 ). A média do peso da parte aérea e da altura das plantas com o produto a $10 \%$ foi significativamente superior à apresentada pela testemunha (Tabela 3 ). Nas concentrações de $20 \%$ e de $40 \%$ houve uma redução na média do número de ovos e de galhas maior que $99 \%$ em relação à testemunha (Figuras 5, 6, 7 e 8). O produto na concentração de 20\%, não mostrou diferença significativa entre a altura e o peso da parte aérea em relação à testemunha. Porém, na concentração de $40 \%$ o peso da parte aérea foi significativamente menor que o apresentado pela testemunha, enquanto que a altura média das plantas não apresentou diferença significativa (Tabela 3).

O produto DS também apresentou alta eficência no controle de $M$. javanica em tomateiro em todas as concentrações testadas. A redução

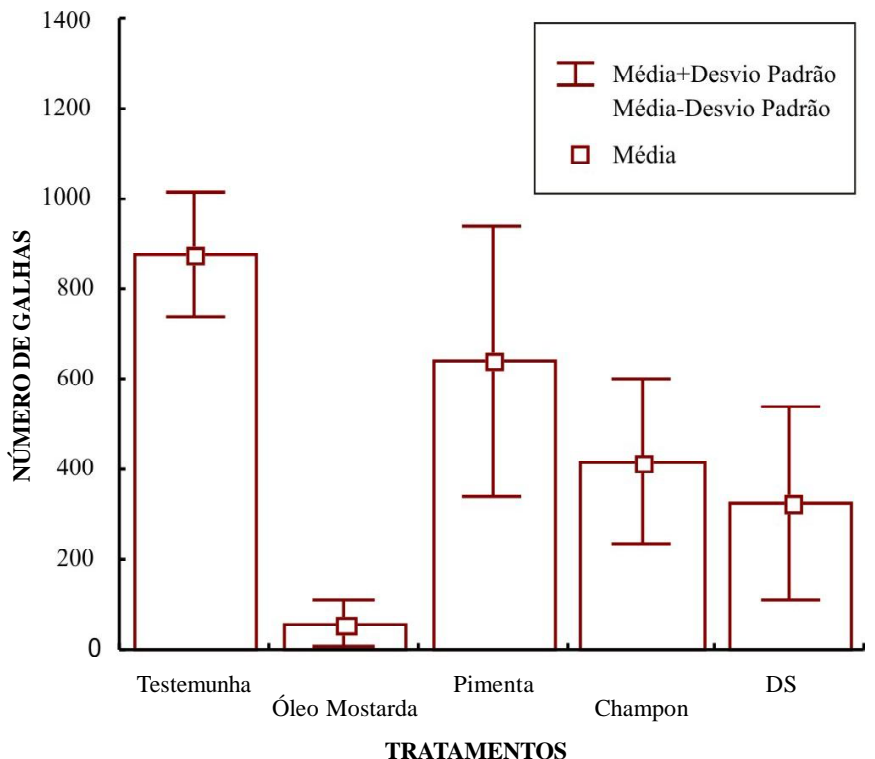

Figura 4: Número de galhas formadas por Meloidogyne javanica em raízes de tomateiro retiradas de solo tratado com extratos na concentração de 100 ppm e dos produtos na concentração de $10 \%$.

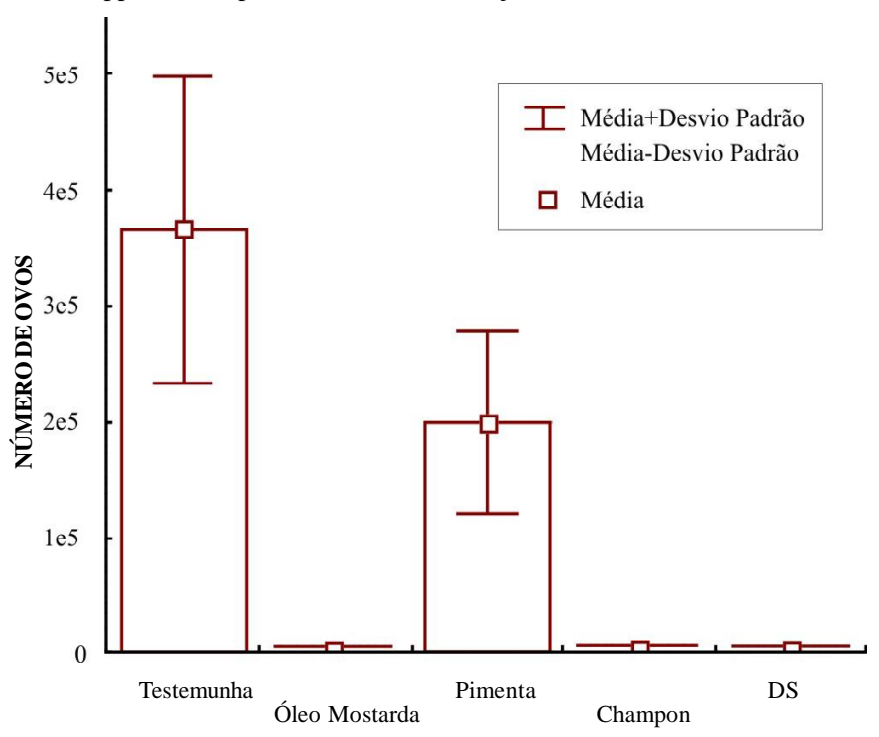

TRATAMENTOS

Figura 5: Número de ovos de Meloidogyne javanica em raízes de tomateiro retiradas de solo tratado com extratos na concentração de 200 ppm e dos produtos na concentração de $20 \%$.

do número de ovos e de galhas, com o produto a $5 \%$, foi de $82,3 \%$ e $53,4 \%$, respectivamente, em relação à testemunha (Figura 1 e 2). A média da altura e do peso da parte aérea com o produto a $5 \%$, foi significativamente maior quando comparados com a testemunha (Tabela 3). Na concentração de $10 \%$, o produto apresentou uma redução de $87,3 \%$ e $95,0 \%$ no número de galhas e de ovos, quando comparados à testemunha (Figuras 3 e 4). A média da altura e do peso da parte aérea das plantas com o produto a $10 \%$ foi significativamente superior à apresentada pela testemunha (Tabela 3). Na concentração de $40 \%$ e $20 \%$ do produto houve uma redução no número de ovos e de galhas maior que $99 \%$ em relação à testemunha (Figuras 5, 6, 7 e 8). Com produto na concentração de $20 \%$ a altura e o peso da parte aérea das plantas não apresentaram diferença significativa em relação a testemunha. Na concentração de $40 \%$ do produto, a altura das plantas 


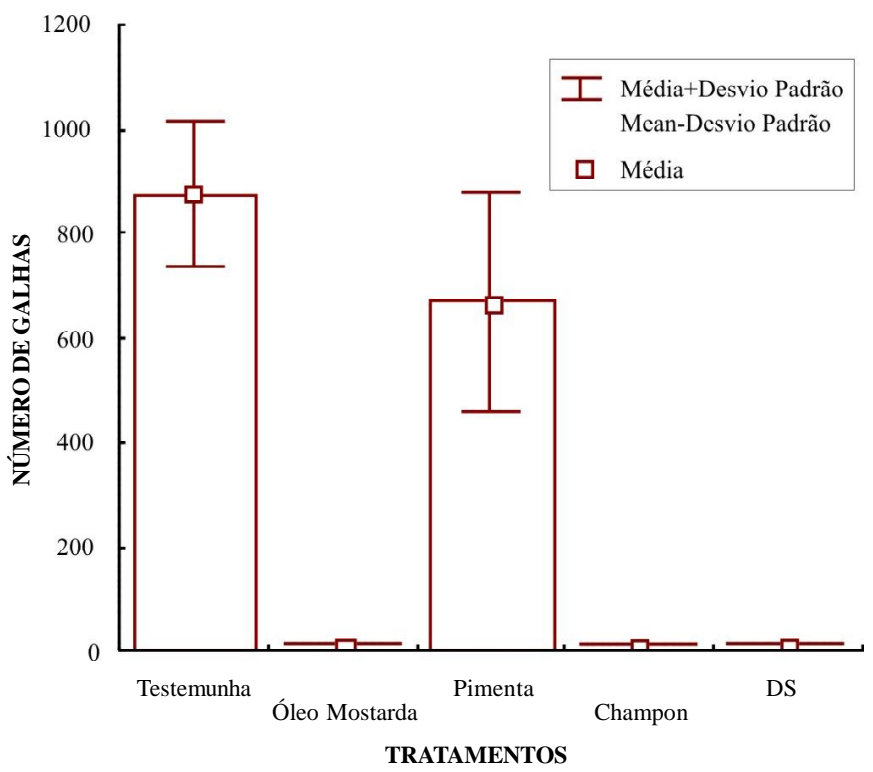

Figura 6: Número de galhas formadas por Meloidogyne javanica em raízes de tomateiro retiradas de solo tratado com extratos na concentração de 200 ppm e dos produtos na concentração de $20 \%$.

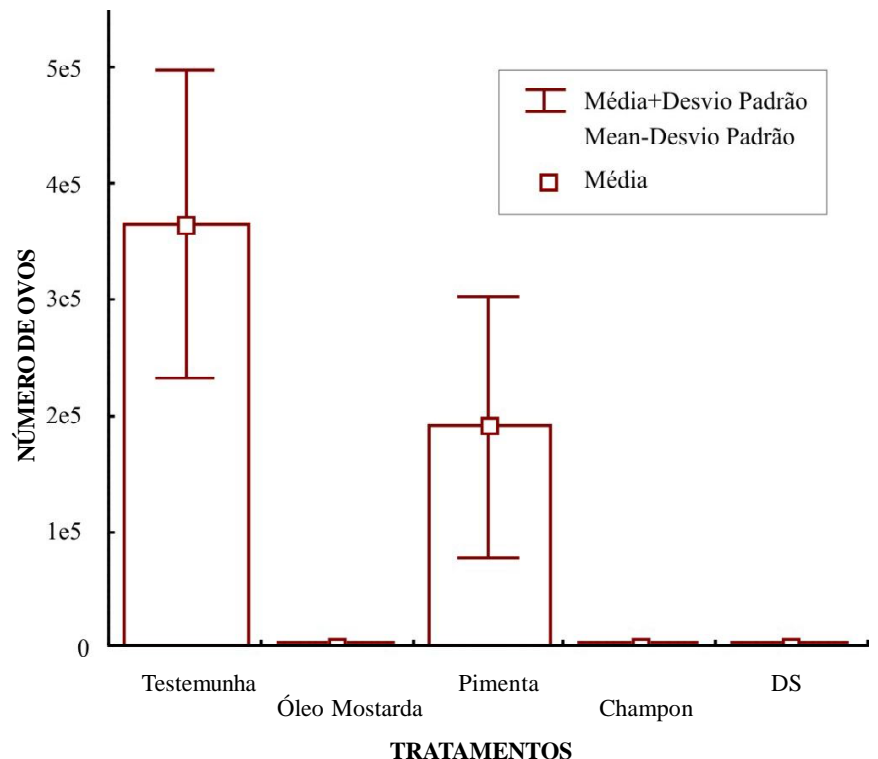

Figura 7: Número de ovos de Meloidogyne javanica em raízes de tomateiro retiradas de solo tratado com extratos na concentração de 400 ppm e dos produtos na concentração de $40 \%$.

não apresentou diferença estatística em relação à testemunha e o peso foi significativamente menor que o apresentado pela testemunha, o que pode indicar um certo nível de fitotoxidez (Tabela 3).

Os resultados obtidos para os dois produtos não demonstram grandes diferenças entre eles quanto a sua eficiência no controle do nematóide. Resultados semelhantes foram obtidos por Freitas et al. (5) com um produto natural com 4,94\% de capsaicina e capsainóides e 4,43\% de alil isotiocianato como ingredientes ativos, em relação ao número de galhas e de ovos, que observaram além disso fitotoxidez, expressa em menor altura de planta e peso de raiz, com o produtos em altas concentrações. Os resultados obtidos talvez sejam devido à presença do composto alil isotiocianato, que é um composto volátil tóxico para fungos e que é um ingrediente ativo de fumigantes do solo comerciais (11). Lazzeri et al. (10) investigaram o efeito de

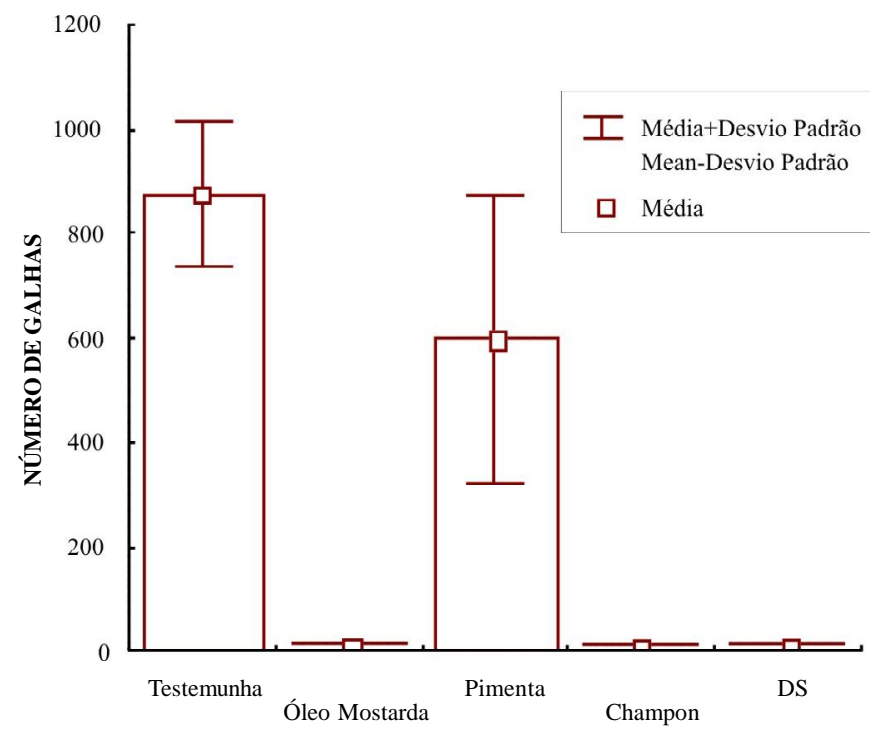

TRATAMENTOS

Figura 8: Número de galhas formadas por Meloidogyne javanica em raízes de tomateiro retiradas de solo tratado com extratos na concentração de 400 ppm e dos produtos na concentração de $40 \%$.

glicosinolatos e de seus produtos sobre o nematóide Heterodera schachtii, observando que alil isotiocianato causou a morte de $100 \%$ dos nematóides após 96 horas de exposição ao produto, "in vitro".

Neste experimento conclui-se que o extrato de pimenta causou redução do número de galhas e de ovos nas concentrações de 400 e 200 ppm e não causou fitotoxidez em nenhuma das concentrações, mas o melhor resultado foi obtido na concentração de 400 ppm onde o número de galhas teve uma redução de $23,5 \%$ e o número de ovos $45,5 \%$ em relação à testemunha. $\mathrm{O}$ óleo de mostarda apresentou alta eficiência em relação a redução do número de galhas e de ovos e a concentração mais indicada foi a de $10 \%$, onde houve redução de $99 \%$ do número de galhas e de ovos e apresentou plantas com altura e peso significativamente maiores que a testemunha. Os dois produtos testados, Champon e DS, também foram eficientes em todas as concentrações, mas a concentração de $20 \%$ foi a que apresentou melhor resultado quanto a redução do número de ovos e de galhas sem a ocorrência de fitotoxidez.

\section{AGRADECIMENTOS}

Ao Professor Antônio Jacinto Demuner do LASA ( Laboratório de Análise e Síntese de Agroquímicos), pertencente à Universidade Federal de Viçosa, pela ajuda na obtenção dos extratos. Ao CNPq e à FAPEMIG pelo apoio financeiro.

\section{REFERÊNCIAS BIBLIOGRÁFICAS}

1. AKTAR, M. \& MAHMOOD, I. 1993. Control of plant parasitic nematodes with "nimim" and some plant oils by bare-root dip treatment. Nematologia Mediterranea, Bari. 21(1): 89-92.

2. BONETI, J.I.S., FERRAZ, S. 1981. Modificação do método de Hussey \& Barker para extração de ovos de Meloidogyne exigua de raízes de cafeeiro. Fitopatologia Brasileira, 6: 553.

3. EUCLYDES, R.F. 1983. Sistema para análise estatística genética: SAEG. Viçosa, MG: UFV, 57p.

4. FERRIS, H. \& ZHENG, L. 1999. Plant sources of chinese herbal 
remedies: effects on Pratylenchus vulnus and Meloidogyne javanica. Journal of Nematology 31(3): 241-263.

5. FREITAS, L.G.; MARRA, B.M.; NEVES, W.S. \& MOREIRA, J.U.V. 2000. Controle de Meloidogyne javanica com extratos de pimenta malagueta (Capsicum frutenscens) e mostarda (Brassica campestris). In: CONGRESSO BRASILEIRO DE FITOPATOLOGIA. Belém, Resumos, p.336.

6. GOSWAMI, B.K. \& K. VIJAYALAKSHMI. 1981. Effect of some indigenous plant materials and oil-cakes amended soils on the growth of tomato and root-knot nematode population. Indian Journal of Nematology 11: 121. 1981.

7. GUPTA, R. \& SHARMA, N.K. 1991. Nematicidal properties of garlic, Allium sativum. Indian Journal Nematology, New Delhi 21: $14-18$.

8. HUSAIN, S.I.; KUMAR, R.; KHAN, T.A. \& TITOV, A. 1984 Effect of root-dip treatment of egg plant seedlings with plant extracts and anthelmintic drugs on plant growth and root-knot development. Pakistanian Journal of Nematology 2(2): 79-83.

9. HUSSAINI, S.S.; RAO, R.V.V.P. \& PANDU, H.K. 1996. Toxicity of water soluble leaf extracts against larvae and egg masses of three Meloidogyne species. Indian Journal of Nematology 26(1): 23-31.

10. LAZZERI, L.; TACCONI, R. \& PALMIERI, S. 1993. In vitro activity of some glucosinolates and their reaction products toward a population of the nematode Heterodera schachtii. Journal Agric. Food Chemical 41:825-829.

11. LEWIS, J. A. \& PAPAVIZAS, G.C. 1971. Effect of sulfur-containing volatile compounds and vapors from cabbage decomposition on Aphanomyces euteiches. Phytopathology 61: 208-214.

12. MANI, A. \& CHITRA, K.C. 1989. Toxicity of certain plant extracts to Meloidogyne incognita. Nematologia Mediterranea 17: 43-44.

13. MATEEVA, A.; IVANOVA, M.; GULLINO, M.L.; KATAN, J. \& MATTA, A. 2000. Alternative methods for control of root-knot nematodes, Meloidogyne spp. Acta Horticulturae, 532: 109-111.

14. MAYTON, H.S.; CLAUDIA, O.; VAUGHN, S.F. \& LORIA, R. 1996. Correlation of fungicidal activity of Brassica species with allyl isotiocianate production in macerated leaf tissue. Phytopathology, 86: 267-271.

15. MOREIRA, J.U.V. \& FREITAS, L.G. 1998. Efeito do filtrado de pimenta malagueta (Capsicum frutescens L.) sobre a infectividade de Meloidogyne javanica em raízes de tomateiro. Fitopatolo- gia Brasileira, Brasília, 23(suplemento): 306 (resumo).

16. NATH, A.; SHARMA, N.K.; BHARDMAJ, S. \& THAPA, C.D. 1982. Nematicidal properties of garlic. Nematologica 28: 253255.

17. NIDIRY, E.S.J.; CHANDRAVADANA, M.V.; KHAN, R.M. \& RAO, M.S. 1994. In vitro nematicidal activity of extracts of bulbs and seeds onion against root-knot nematode Meloidogyne incognita. Nematologia Mediterranea, 22: 31-40.

18. PAPAVIZAS, G.C. 1968. Supression of Aphanomyces root rot of peas by cruciferous soil amendments. Phytopatology 56: 10711075.

19. PAPAVIZAS, G.C. 1967. Comparision of treatments suggested for control of Aphanomyces root rot of peas. Plant Disease 51: 125-129.

20. PARADA, R.Y. \& GUZMÁN, R.F. 1997. Evaluacion de extractos botanicos contra el nematodo Meloidogyne incognita en frijol (Phaseolus vulgaris). Agronomia Mesoamericana - Nota Técnica 8(1): 108-114.

21. POTER, M.J.; DAVIES, K.; RATHJEN, A.J. 1998. Supressive impact of glucosinolates in Brassica vegetative tissues on root lesion nematode Pratylenchus neglectus. Journal of Chemical Ecology 24(1): 67-68.

22. RAO, M.S. \& REDDY, P.P. 1992. Studies on the comparative efficacy of certain plant leaves and carbofuran in the management of Meloidogyne incognita on tomato. Current Nematology 3(1): 5-6.

23. SASSER, J. N. 1989. Plant parasitic nematodes: The farmer's hidden enmy. Publication Department of Plant Pathology and the Consortium for International Crop Protection. 114p.

24. SASSER, J. N., \& FRECKMAN, D. W. 1987. A world perspective on nematology: the role of the society. In: J. A. VEECH \& D. W. DICKSON, (Ed.) Vistas on Nematology. Maryland: Society of Nematologists, p. 7-14.

25. SCRAMIN, S.; SILVA, H.P.; L.M.S. FERNANDES, L.M.S. \& YHAN, C.A. 1987. Avaliação biológica de extratos de 14 espécies vegetais sobre Meloidogyne incognita raça 1. Nematologia Brasileira 11: 89-101.

26. SUKUL, N.C.; DAS, P.K. \& DE, G.C. 1974. Nematicidal action of some edible crops. Nematologica 20: 187-191.

27. TARJAN, A.C. 1990. Tests with ubiquitous materials for biocontrol of Meloidogyne incognita infecting tomato plants. Nematologia Mediterrânea, 18: 231-232. 